ManN, S. O. \& OXford, A. E. (1955). J. gen. Microbiol. 12, 140-146.

\title{
Relationships between Viable Saccharolytic Bacteria in Rumen and Abomasum of the Young Galf and Kid
}

\author{
By S. O. MANN AND A. E. OXFORD \\ Rowett Research Institute, Bucksburn, Aberdeenshire
}

SUMMARY: The abomasums of three very young calves and two kids, of which all, save one suckled kid, had been fed on milk by bottle, were found to be supporting large populations of lactobacilli of both homo- and heterofermentative types. The heterofermentative organisms in every instance corresponded in fermentation reactions to Lactobacillus fermenti and was also found in one calf's rumen. The single homofermentative strain isolated from a calf was very near to L. acidophilus in fermentation reactions. The kid abomasum homofermentative isolates all seemed to belong to a new and unusual variety of $L$. acidophilus (var. caprae). It was amylolytic, insensitive to aureomycin, and hydrolysed aesculin.

The rumen and abomasum of the young calf contained an atypical variety of amylolytic streptococcus, differing from the typical Streptococcus bovis of the adult rumen in being non-haemolytic and in fermenting mannitol. The typical rumen $S$. bovis is sometimes truly iodophilic. These rumen and abomasum streptococci and lactobacilli are probably not introduced via the milk.

In a previous paper (Mann \& Oxford, 1954) we described some lactobacilli belonging to both homo- and heterofermentative types, which had been found occasionally in the rumen contents of young ruminating calves up to 8 weeks of age only. We now add a description of the Gram-positive cocci accompanying them in that situation with especial reference to the change from nonand atypical amylolytic streptococcal types to the typical rumen amylolytic streptococcus (as described by MacPherson, 1953) with increasing age of the calf up to 14 weeks. Although the abomasum contents of the adult ruminant are usually much too acid to support bacterial growth, this is not always so with the young calf, as was shown by Mann, Masson \& Oxford (1954b) in an aureomycin-feeding experiment. It seemed worth while therefore to attempt to isolate aciduric bacteria (particularly lactobacilli) from the abomasum as well as the rumen of the 10-day old calf before rumination had become properly established, and thus to compare the respective microfloras before that of the rumen became specialized. We have also extended the investigation to young kids of the same age, since, as will be seen, their abomasum contents are quite acid from the beginning and unlikely to support any but extremely aciduric species.

\section{METHODS}

Examination of Gram-positive cocci isolated from the rumens of nine calves. These cultures comprised the 69 isolates which, as mentioned by Mann \& Oxford (1954), accompanied the lactobacilli described in that paper. They were obtained from the rumen contents of nine slaughtered calves belonging to three age-groups, with three calves in each group. These age-groups, subsequently 
referred to as 1, 2 and 3, were approximately 5,8 and 14 weeks old, respectively. The cultures were isolated from parallel series of bottle counts in which cellobiose and mannitol provided the respective carbohydrate substrates. They were studied in detail by the methods described by Mann, Masson \& Oxford $(1954 a)$ for sheep rumen streptococci and micrococci.

Examination of bulk contents of rumen and abomasum of very young calves and kids. In each of the months of March, April and May 1954, a week-old Ayrshire bullcalf (hereafter denoted CF 1, CF 2 or CF 3) was purchased from a nearby farm and maintained in isolation for 3 or 4 days, before slaughter, on the usual ration of milk and 'starter' gruel. Although each calf had begun to nibble straw, in no instance was it really ruminating. Two very young kids (denoted K 1 and K 2), which had been born and bred in the Institute, were also slaughtered during the same period. $\mathrm{K} 1$ had been maintained by bottle on goat milk from birth, while $\mathrm{K} 2 \mathrm{had}$ been suckled continuously. It had, however, begun to nibble straw before it was slaughtered. In each case the rumen and abomasum contents were separately worked up within an hour of slaughter, the weights, $\mathrm{pH}$ values, visible presence or absence of coagulated milk being noted. Direct smears were heat fixed and stained by Gram's method, chiefly to determine whether or not Gram-positive rods were present in numbers.

Isolation of lactobacilli from rumen and abomasum of the very young calf and kid. The 'bottle count' previously referred to was modified for this purpose as follows. Serial dilutions of rumen or abomasum contents, usually up to $10^{-6}$ or sometimes $10^{-8}$, were made in sterile quarter-strength Ringer's solution; $1 \mathrm{ml}$. of each dilution was added to $15 \mathrm{ml}$. sterile molten $\left(45^{\circ}\right)$ tomato extract agar ( $\mathrm{pH} \mathrm{5.9)}$ prepared according to the directions of Rogosa, Wiseman, Mitchell, Disraely \& Beaman (1953). The carbohydrate added to the medium was glucose. The subsequent procedure was as described by Mann \& Oxford (1954).

Isolation of streptococci from rumen and abomasum contents of a very young calf. Not all the colonies which developed in the bottle counts proved to be lactobacilli; some were streptococci. These latter were ignored in the case of the kid since there exists at present no background of knowledge concerning streptococcal types in the adult goat rumen. With one calf, however (CF 2, from the abomasum of which no homofermentative lactic acid organisms were isolated) an attempt was made to compare the predominant streptococcal types in rumen and abomasum respectively by the methods of Mann et al. $(1954 a)$.

\section{RESULTS}

Classification of calf rumen streptococci according to age of calf

It was possible to isolate streptococci in pure culture from the rumen of eight of the nine calves in the three age-groups referred to. The one exception, the oldest calf, yielded only micrococci (see below). Some 15-20 rumen streptococcal isolates were obtained in all from each age-group. Only one-third of these were amylolytic in age-group 1 , while more than two-thirds were amylolytic in each of the older age-groups. Some of these isolates were iodophilic, i.e. 
gave colonies on starch or maltose agar after 4 days incubation which became intensely blue-black when the plate was flooded with Lugol's iodine. These interesting rumen streptococci, the first of their kind to be isolated in pure culture, will be reported upon in a subsequent paper.

It was probable that all these rumen streptococci belonged to Lancefield's serological group D. Eleven isolates taken at random, including representatives from every calf age-group, were grouped by Fuller's (1938) formamide method. No extract reacted with Lancefield's group B antiserum; all save one reacted with group $\mathbf{D}$ antiserum. The one exception belonged to the middle age-group, but was not regarded as significant because three other isolates from this group reacted.

Although several amylolytic streptococci belonging to group $\mathbf{D}$ were isolated from age-group 1, they were not identical with the typical rumen amylolytic streptococcus of MacPherson (1953) which was, however, frequently obtained from the older calves' rumens. They rather resembled the atypical rumen amylolytic streptococcus encountered by Mann et al. (1954a) in the sheep's rumen. This atypical organism was not however encountered at all in calf age-group 3. It differs from the typical form chiefly in being always nonhaemolytic, in giving larger and whiter colonies, and in fermenting mannitol. The fermentation and other reactions of 58 calf rumen streptococcal isolates are summarized in Fig. 1, in which the respective calf age-groups are also taken into account.

\begin{tabular}{|c|c|c|c|}
\hline \multicolumn{4}{|c|}{ Fermentation of starch and inulin } \\
\hline \multicolumn{2}{|c|}{$\begin{aligned}+,+ & (42 \text { isolates }) \\
& \begin{array}{l}\text { Haemolysis and } \\
\text { mannitol fermentation }\end{array}\end{aligned}$} & \multicolumn{2}{|c|}{$\begin{array}{l}0,0 \text { (16 isolates, all } \alpha \text {-haemolytic) } \\
\qquad \begin{array}{l}\text { Growth in } 6.5 \% \mathrm{NaCl} \\
\text { and mannitol } \\
\text { fermentation }\end{array}\end{array}$} \\
\hline $\begin{array}{l}0,+(17 \text { isolates })^{*} \\
\text { from age-groups } 1 \\
\text { and } 2 \text { only; not } \\
\text { from age-group } 3\end{array}$ & $\begin{array}{l}\alpha, 0 \text { (25 isolates) } \dagger \\
\text { from age-groups } 2 \\
\text { and } 3 \text { only; not } \\
\text { from age-group } 1 \\
\text { (some isolates were } \\
\text { iodophilic) }\end{array}$ & $\begin{array}{l}+,+(6 \text { isolates }) \ddagger \\
\text { from age-group } 1 \\
\text { only }\end{array}$ & $\begin{array}{l}0 \text {, variable }(10 \\
\text { isolates }) \text { from all } \\
\text { age-groups }\end{array}$ \\
\hline
\end{tabular}

Fig. 1. Classification of $\mathbf{5 8}$ group $\mathbf{D}$ streptococcal isolates from calf rumen, according to fermentation reactions, and age of calf. $+=$ fermentation or growth where appropriate; $0=$ no fermentation or no growth; $\alpha=\alpha$-haemolysis.

* 'Atypical' rumen amylolytic streptococcus.

$\dagger$ 'typical' rumen amylolytic streptococcus.

† Streptococcus faecalis.

\section{Micrococci from the rumen of a calf in age-group 3}

In this one instance, both the cellobiose and mannitol bottle counts yielded preponderantly staphylococcal colonies. Eight isolates, all coagulasenegative, were studied in detail; six were both VP and MR positive and probably belonged to subgroup 2 of Shaw, Stitt \& Cowan (1951). The remaining two isolates reduced nitrate, were MR positive and VP negative, and might be placed in subgroup 3 of the above classification. It is of interest that all eight isolates were urease-positive (cf. Mackay \& Oxford, 1954). 


\section{Properties of rumen and abomasum contents from three very young calves and two kids}

As the results summarized in Table 1 show, the rumen and abomasum contents of the calves were in general more like each other than was the case with the kids. The rumen was relatively quite small in the supposedly nonruminating kid; nevertheless, its contents had the 'adult' rumen $\mathrm{pH}$ value, and also the appearance and smell of the latter, and was singularly free from coagulated milk. Although the kid abomasum was in each case at $\mathrm{pH} 4$, nevertheless the viable lactobacillus count was quite considerable, and comparable with that of the rather less acid calf abomasum (see Table 1).

Table 1. Characteristics of rumen and abomasum contents of 10-day and 11-day calves and kids

\begin{tabular}{|c|c|c|c|c|c|c|c|}
\hline \multirow[b]{2}{*}{$\begin{array}{c}\text { Calf (CF) } \\
\text { or kid (K) } \\
\text { reference no. }\end{array}$} & \multirow[b]{2}{*}{$\begin{array}{l}\text { Age of } \\
\text { animal } \\
\text { (days) }\end{array}$} & \multicolumn{3}{|c|}{ Rumen-reticulum contents } & \multicolumn{3}{|c|}{ Abomasum contents } \\
\hline & & $\begin{array}{c}\text { Weight } \\
\text { (g.) }\end{array}$ & $\begin{array}{c}\mathbf{p H} \\
\text { value }\end{array}$ & $\begin{array}{l}\text { Viable 'lacto- } \\
\text { bacillus + strepto- } \\
\text { coccus' count } \\
\text { (per } \mu \text { g. rumen } \\
\text { contents) }\end{array}$ & $\begin{array}{l}\text { Weight } \\
\text { (g.) }\end{array}$ & $\underset{\text { value }}{\mathrm{pH}}$ & $\begin{array}{l}\text { Viable 'lacto- } \\
\text { bacillus + strepto- } \\
\text { coccus' count } \\
\text { (per } \mu \text { g. aboma- } \\
\text { sum contents) }\end{array}$ \\
\hline CF 1 & 11 & 1249 & $5 \cdot 7$ & $+*$ & 704 & $5 \cdot 2$ & + \\
\hline CF2 & 11 & 365 & $6 \cdot 0$ & $29 *$ & 530 & $5 \cdot 5$ & $>100$ \\
\hline CF 3 & 10 & 579 & $5 \cdot 8$ & $>100$ & 616 & $4 \cdot 3$ & $>100$ \\
\hline K1 & 10 & 20 & $6 \cdot 1$ & $>100^{*}$ & 210 & $4 \cdot 0$ & $13 \dagger$ \\
\hline K2 & 11 & 61 & $6 \cdot 7$ & $>1000^{*}$ & 186 & $4 \cdot 0$ & $>1000 \dagger$ \\
\hline
\end{tabular}

* Chiefly streptococei; $\dagger$ chiefly lactobacilli; $+=$ numerous, but no exact count made.

\section{Presence of lactobacilli as revealed by direct smears from rumen and abomasum contents of calves and kids}

Gram-positive rods were always abundant in smears from the abomasum. They were usually long, often curved and were accompanied, as in the pure cultures of lactobacilli obtained from this situation, by degenerate Gramnegative forms of similar morphology. The rumen picture was always much more heterogeneous, with Gram-positive rods very much in the minority, and usually, when these occurred, they were not very similar to those in the corresponding abomasum smear, being smaller and more uniform in appearance. Gram-negative cocci were usually plentiful in rumen smears; Gram-positive cocci were rather less abundant, but still plentiful. It was concluded that although rumination had not become really established, the rumen microflora looked not very dissimilar from what would be expected for a more adult animal.

Properties of Gram-positive rod isolates (lactobacilli) from rumen of calf $\mathrm{CF} 1$ and from abomasum contents in three young calves and two kids

Several isolates were made and purified in each instance. All were catalasenegative and did not reduce nitrate, i.e. were presumptive lactobacilli. Since it happened that all the heterofermentative, and (when isolated) all the 
homofermentative lactic acid organisms isolated from any given rumen or abomasum were in every instance virtually indistinguishable from each other, it is not necessary to list the properties and fermentation reactions of the 32 isolates individually. Further examination showed that all the 19 heterofermentative isolates really belonged to one species, no striking differences existing. Thus, all fermented arabinose (but not xylose), galactose, glucose, lactose, maltose, melibiose, raffinose and sucrose but no other carbohydrate save fructose inconstantly. They did not hydrolyse aesculin nor attack hippurate. All grew at $45^{\circ}$ but not at $16^{\circ}$. Lactobacillus fermenti rather than L. brevis seemed to be the species which would include all these heterofermentative isolates. The organism was isolated from all five abomasums examined and also from the most acid calf rumen, viz. that of CF1 (two isolates).

The homofermentative lactic acid organisms isolated from the two kid abomasums and also from the most acid calf abomasum (CF3) only, showed more diversity in fermentation reactions. The kid isolates were all very similar and had rather wider fermentative powers than the calf isolates which again were all very similar. The former ( 7 isolates in all, of which 5 were from K1) fermented cellobiose, dextrin, fructose, galactose, glucose, lactose, maltose, mannose, salicin, starch and sucrose with depression of $\mathrm{pH}$ to 3.9 in most instances; and also hydrolysed aesculin. The latter ( 6 isolates) did not ferment dextrin, maltose or starch, but unlike the kid isolates did attack trehalose in addition to the remaining sugars mentioned above with production of an acid $\mathrm{pH}$ value (3.9). Aesculin was not hydrolysed by the calf isolates. All these homofermentative isolates produced inactive lactic acid from glucose and tended to give rough colonies. All formed long rods and grew best under microaerophilic conditions; none grew at $16^{\circ}$. It was concluded that Lactobacillus acidophilus (cf. Rogosa et al. 1953) would cover the whole range of these homofermentative organisms, but that the kid strains, because being able to ferment starch and dextrin and to hydrolyse aesculin, might belong to a hitherto unnoticed variety in this species, which might be called $L$. acidophilus var. caprae since it was obtained from goat abomasum, concerning which situation no previous microbiological knowledge seems to exist. Unlike $\boldsymbol{L}$. acidophilus from calf rumen both isolates of $\boldsymbol{L}$. acidophilus var. caprae were quite resistant to aureomycin in glucose tomato extract broth, requiring instead of $4 \mu \mathrm{g} . / \mathrm{ml}$. at least $64 \mu \mathrm{g} . / \mathrm{ml}$. for complete inhibition of growth.

\section{Streptococcal isolates from the rumen and abomasum of calf $\mathrm{CF} 2$}

These comprised 13 isolates from rumen and 3 from abomasum. They were isolated by use of the rich tomato-extract agar medium (see Methods) instead of the rumen liquor agar of Mann et al. (1954a) and so are not strictly comparable with the $\mathbf{5 8}$ calf rumen streptococcal isolates previously classified in this paper. All 16 isolates were amylolytic; 6 from rumen and all 3 from abomasum belonged to the atypical rumen amylolytic streptococcus of Fig. 1. The remaining 7 isolates of which 5 were iodophilic, belonged to the typical rumen amylolytic streptococcus of Fig. 1. 


\section{Aciduric bacteria in fresh milk fed to the calves}

When treated as for rumen contents, diluted and inoculated into glucose tomato-extract agar as previously described, the fresh milk yielded only streptococci in small numbers. Three isolates were tested and found not to be amylolytic; lactobacilli were never encountered.

\section{DISCUSSION}

The results make it clear that the abomasums of the very young calf and kid both support a large and diverse population of lactobacilli. Since, as Trautmann \& Schmitt (1933) have shown, a back-flow of milk from abomasum to rumen may occur after feeding, and since food may pass direct to the abomasum in the young ruminant via the oesophageal groove, it is quite possible that the lactobacilli sporadically found in the calf rumen, both in this study and previously by Mann \& Oxford (1954), may not normally be multiplying there but merely have been introduced from the abomasum where conditions are very favourable for their multiplication as long as the $\mathrm{pH}$ value remains at 4 or greater. The solitary calf rumen lactobacillus isolated did in fact belong to the same species (probably Lactobacillus fermenti) as found in the abomasum of the same calf (CF 1 ).

None of the lactobacilli isolated in this study belong to species previously isolated from rather older calves by Mann \& Oxford (1954). It is possible that it is a matter of chance which lactobacillus from the outside world finds a lodgement in the young ruminant's abomasum. The conditions there would be suitable for almost any microaerophilic lactose-fermenting lactobacillus with optimum temperature about $38^{\circ}$ to multiply quickly. The results tend to indicate that such lactobacilli come from the solid food (straw?) or the mother's saliva, rather than milk. It is unlikely, for example, that the suckling kid (K2) could have taken in any lactobacilli with its mother's milk, yet it had a large population of these bacteria in its abomasum.

The present study also indicates that the typical rumen amylolytic streptococcus of the adult animal, although sometimes present in the young calf, does not become properly established until the rumen $\mathrm{pH}$ value is stabilized near neutrality. This seems not to happen until the calf is several weeks old (cf. Mann et al. 1954 b). In the rumen of the very young animal, a somewhat different amylolytic streptococcus is to be found, which is possibly more tolerant of a smaller pH value. Both organisms, however, belong to Lancefield's group D and may be regarded as varieties of Streptococcus bovis, as defined in Bergey's Manual (1948).

We are indebted to Dr Margaret I. Chalmers of this Institute for placing the two kids at our disposal. 


\section{REFERENCES}

Bergey's Manual of Determinative Bacteriology, 6th ed. (1948). Ed. by Breed, R. S., Murray, E. G. D. \& Hitchens, A. P. London: Baillière, Tindall and Cox.

Fuller, A. T. (1938). The formamide method for the extraction of polysaccharide from haemolytic streptococci. Brit. J. exp. Path. 19, 130.

Mackay, E. S. M. \& Oxford, A. E. (1954). Some facultatively anaerobic Gramnegative rods from the rumen of the calf and the sheep. J. gen. Microbiol. 11, 472.

MacPherson, M. J. (1953). Isolation and identification of amylolytic streptococci from the rumen of the sheep. J. Path. Bact. 66, 95.

Mann, S. O., Masson, F. M. \& Oxford, A. E. (1954a). Facultative anaerobic bacteria from the sheep's rumen. J. gen. Microbiol. 10, 142.

ManN, S. O., Masson, F. M. \& OXFord, A. E. (1954b). Effect of feeding aureomycin to calves upon the establishment of their normal rumen microflora and -fauna. Brit. J. Nutr. 8, 246.

MANN, S. O. \& OxFord, A. E. (1954). Studies of some presumptive lactobacilli isolated from the rumens of young calves. J. gen. Microbiol. 11, 83.

Rogosa, M., Wiseman, R. F., Mitcheli, J. A., Disraely, M. N. \& Beaman, A. J. (1953). Species differentiation of oral lactobacilli from man including descriptions of Lactobacillus salivarius nov. spec. and Lactobacillus cellobiosus nov. spec. J. Bact. 65, 681.

Shaw, C., StitT, J. M. \& Cowan, S. T. (1951). Staphylococci and their classification. J. gen. Microbiol. 5, 1010.

Trautmann, A. \& Schmitt, J. (1933) Über den regelmässigen Rückfluss von Milch aus dem Labmagen in die Vormägen beim jugendlichen Wiederkäuer. Arch. Tierernähr. Tierz. 9, 11.

\section{ADDENDUM}

After the completion of this work we noted that a strongly amylolytic and salicin-fermenting strain of $L$. acidophilus had very recently been isolated by Harrison \& Hansen (1954) from blackhead liver lesions in turkeys. Their isolates, however, unlike our L. acidophilus (var. caprae), all fermented raffinose.

\section{REFERENCE}

Harrison, A. P. \& Hansen, P. A. (1954). Characterization of the Lactobacteriaceae encountered as secondary invaders in blackhead liver lesions of turkeys. $\mathbf{Z b l}$. Bakt. (1 Abt. Orig.), 161, 125. 